Dicenda. Estudios de lengua y literatura españolas

ISSN-e: $1988-2556$

https://dx.doi.org/10.5209/DICE.65002

\title{
La imagen de la mujer en la narrativa de la División Azul (1941-1978)
}

\author{
Jesús Guzmán Mora ${ }^{1}$
}

Recibido: 9 de junio de 2017 / Aceptado: 25 de octubre de 2018

Resumen. Los voluntarios de la División Azul escribieron varias novelas y memorias sobre su experiencia en la II Guerra Mundial. Entre los temas que aparecen en ellas destaca la relación que mantuvieron los soldados con las mujeres españolas — enfermeras y madrinas de guerra-, alemanas y rusas. El objetivo de este artículo es analizar el papel de la mujer en la narrativa de los ex-combatientes hasta 1978. Después de esto, se observará el caso de El desconocido (1956), de Carmen Kurtz, el único libro acerca de la División Española de Voluntarios escrito por una mujer en la dictadura. Aquí se aprecia una perspectiva novedosa: el papel protagonista recae sobre la esposa que vuelve a vivir con su marido tras el regreso de este del Gulag soviético.

Palabras clave: División Azul; Literatura divisionaria; Mujer en el franquismo; Carmen Kurtz.

\section{[en] The Image of the Woman in the narrative of the Spanish Blue Division (1941-1978)}

\begin{abstract}
The volunteers of the Spanish Blue Division wrote some novels and memories about their experience in the Second World War. Among the topics that appear in them, stands out the relationship that the soldiers maintained with the Spaniards — nurses and war godmothers-, Germans and Russians women. The aim of this essay is to analyze the female role in the narrative about the Spanish volunteers in the Soviet Union until 1978. After that, I study the example of El desconocido (1956) by Carmen Kurtz, the only book about the Spanish Blue Division written by a woman during the dictatorship. We can thus appreciate a new perspective: the main character is the wife, who lives again with her husband after his return from the Soviet Gulag.
\end{abstract}

Keywords: Spanish Blue Division; Literature and Spanish Blue Division; Women in the Franco's regime; Carmen Kurtz.

Sumario: 1. Introducción; 1.1. La División Azul: entre la historia y la literatura; 1.2. Mujer y División Azul; 2. La imagen de la mujer en la narrativa divisionaria; 2.1. Madrinas de guerra y enfermeras: las españolas; 2.2. Fräulein y pañenkas: las alemanas y las soviéticas; 2.3. La óptica femenina: El desconocido (Carmen Kurtz, 1956); 3. Conclusiones.

Cómo citar: Guzmán Mora, J. (2019). La imagen de la mujer en la narrativa de la División Azul (19411978), en Dicenda. Estudios de Lengua y Literatura Españolas, 37, 227-253.

\footnotetext{
1 Universidad de Castilla-La Mancha (Programa Universitario “José Saramago 50 Plus”) jesus.guzmanmora@gmail.com
} 


\section{Introducción}

El 21 de junio de 1941 comenzó la Operación Barbarroja, es decir, la invasión de la Unión de Repúblicas Socialistas Soviéticas (URSS) por parte de las tropas del Tercer Reich alemán. Tres días después, una manifestación recorrió las calles de Madrid para pedir la participación de España en el frente del Este de la II Guerra Mundial. Alentada por "los agentes del servicio de información e investigación y los mandos del Sindicato Español Universitario" (Rodríguez Jiménez, 2007: 45), finalizó frente al balcón de la sede de Falange en la calle de Alcalá. Desde allí, Ramón Serrano Suñer pronunció su conocida arenga acerca de la culpabilidad de la nación soviética de la Guerra Civil y la muerte de José Antonio Primo de Rivera en Alicante el 20 de noviembre de 1936 (Moreno Juliá, 2005: 75). Estas palabras pueden considerarse como el discurso fundacional de la División Española de Voluntarios.

Desde este momento y hasta la disolución de la División Azul en octubre de 1943 y la Legión Azul unos meses después, conocidas así por el predominio de Falange en su organización y formación, pasaron por ellas cerca de 45.000 hombres. Con este primer dato podemos afirmar que la División fue una empresa principalmente masculina. A pesar de este hecho, su historia quedaría incompleta si se dejara de lado a las enfermeras que los acompañaron hasta la URSS, las madrinas de guerra a las que dirigían sus cartas y las jóvenes que colaboraban en los envíos de prendas de abrigo y del aguinaldo navideño que organizaba la Sección Femenina de Falange. Asimismo, nadie podría olvidarse de las mujeres originarias de los lugares de paso - alemanas y soviéticas - y con las cuales se relacionaron.

Nuestro interés por la División nos lleva a preguntarnos cómo se representó a las mujeres en el campo literario en aquellas memorias y novelas que, entre 1941 y 1978, tomaron a la División Azul como tema principal en sus narraciones. Estamos de acuerdo con Xosé M. Núñez Seixas cuando ha señalado que este tipo de textos constituyen "una suerte de subgénero dentro de la literatura fascista española" (2005: 94). En nuestro estudio organizaremos esta cuestión en torno a tres cuestiones: la visión que se ofreció de las mujeres españolas, la imagen dada acerca de las alemanas y las soviéticas y, por último, nos acercaremos a la óptica femenina sobre esta cuestión a través de la novela El desconocido, de Carmen Kurtz y ganadora en el año 1956 del Premio Planeta. Aunque ahondaremos en ella más abajo, anunciamos que se trata de una de las obras más interesantes de una autora de gran éxito en su día y que hoy se encuentra en los márgenes del canon literario, por lo que nuestro trabajo sirve también como reivindicación de la propia Kurtz. Pero, antes de llegar a este punto, completaremos la introducción a este ensayo con dos subapartados. En el primero dialogaremos con la bibliografía histórica y literaria de la División Azul. Aquí aprovecharemos para comentar algunos aspectos del corpus de textos, así como justificaremos la selección de los límites temporales. Y en el segundo veremos las cuestiones de las identidades nacional y de género en torno al modelo de mujer propuesto durante los primeros años de la postguerra española desde el poder dictatorial.

\subsection{La División Azul: entre la historia y la literatura}

En los últimos años, la División Azul ha sido motivo de varias monografías históricas que han actualizado el tema y han superado visiones glorificadoras sobre la unidad de voluntarios. La consulta de fuentes que iban más allá de la literatura pu- 
blicada por los miembros de la unidad ha aportado diferentes puntos de vista sobre la misma. Xavier Moreno Juliá (2004) publicó un completo estudio acerca del grupo que traza dos ejes, ya que recorre los sucesos acontecidos en la URSS y en España, por lo que es posible seguir la trayectoria de los divisionarios y de los movimientos políticos en el seno del franquismo. La visión de Xosé M. Núñez Seixas (2016) aporta interesantes conceptos para el estudio del tema divisionario, como la distinción entre el ruso real conocido por los soldados frente al ruso imaginado a través de la propaganda franquista, la posición de los españoles frente al Holocausto como bystanders o el largo final de quienes lucharon por las calles de Berlín, un filonazismo en el que tuvo bastante que ver el sacerdote vasco Martín de Arrizubieta. El ensayo de Jorge M. Reverte (2011) debe leerse como tal y no como un libro estrictamente histórico, al contener interesantes tintes personales ya que su padre, Jesús Martínez Tessier, fue miembro de la División Azul. Este libro y el publicado por José Luis Rodríguez Jiménez (2007) han sido fuertemente criticados desde posiciones a las que puede denominarse - bajo nuestro punto de vista con acierto - "prodivisionaria[s]" (Moreno Juliá, 2005: 324). El primero ha sido rebatido por Francisco Torres García, autor de un reciente ensayo sobre los presos de la División Azul en el Gulag (2018). Este autor hace referencia a un artículo periodístico de Reverte, que sirvió como preludio para la publicación de su libro, acerca del cual dice Torres García que se trata de un "manipulador", "falsario" e "historietista" ( $\sin$ fecha). El segundo ha recibido ataques más duros y que creemos inmerecidos. Estos proceden de un movimiento de academistas conservadores que se autodenominan como "la Otra Memoria" (Bullón de Mendoza, 2011: 15). Carlos Caballero Jurado ha dicho lo siguiente del texto de Rodríguez Jiménez:

La muy bien organizada ofensiva propagandística en torno a la "recuperación de la Memoria Histórica" ha acabado generando un cierto ambiente intelectual en el que parece que solo el bando franquista cometió atropellos y violencias durante la Guerra Civil, así como que prácticamente todos los habitantes de España estuvieron sometidos en la postguerra a un régimen de terror y humillación por el franquismo. Tener en cuenta la violencia política ejercida, y con auténticos rasgos de terror de masas, por el Frente Popular es un elemento que desaparece en los análisis de ciertos autores cuando se habla de los motivos de los divisionarios. El caso más llamativo es, quizá, el de José Luis Rodríguez Jiménez, autor de una obra titulada De héroes e indeseables. La División Azul. El libro, plagado de errores e insidias, pretende sugerir que una gran parte de los divisionarios lo fueron contra su voluntad, pues se vieron reclutados a la fuerza en los cuarteles; aún más, según este autor habría entre ellos un elevado número de antiguos frentepopulistas deseosos de desertar. Así, la División Azul habría estado compuesta en gran medida por personas a quienes sus mismos mandos etiquetaban de "indeseables". Tan dis-

2 Evidentemente, la labor de ciertos los sectores encargados de la recuperación de la memoria de las víctimas de la dictadura no siempre ha sido irreprochable y se ha identificado a la gestión inadecuada del pasado traumático que T. Todorov ha clasificado como "los abusos de la memoria" (2000: 32). Un interesante ejemplo de ello puede verse en una de las novelas de A. Trapiello: "se diría que la Ley de la Memoria Histórica, en vez de conservar para el Estado el monopolio de las reparaciones y la dignificación de las víctimas, permite que los oportunistas busquen únicamente su provecho personal, no la verdad, repitiendo una ficción que creen real sólo por habérsela repetido tantas veces. No es ficticio, sin embargo, el poder que han obtenido con ello: disponen del dinero del Ministerio de la Presidencia, de la Universidad, de algunos ayuntamientos" (2012: 108). 
paratada tesis ha sido expuesta de forma aún más descarnada por el mismo autor en comunicaciones y artículos (2011: 806-807).

No es nuestra intención hacer del artículo un extenso comentario sobre la cuestión historiográfica, pero consideramos que los cuatro ejemplos expuestos arriba - Moreno Juliá, Rodríguez Jiménez, Reverte y Núñez Seixas- se mueven en los parámetros del rigor historiográfico para tratar el tema divisionario. La publicación de Caballero Jurado, incluida dentro del trabajo colectivo dirigido por Bullón de Mendoza, apareció bajo el sello de Actas, editorial en la que de acuerdo con Jordi Gracia "late una nostalgia política o una afinidad ideológica con el falangismo" y se "estudian con atención las novelas de los falangistas más tozudos (...) con voluntad rehabilitadora de su memoria" (2006: 88-89). Menos conocidos, pero en la misma línea, se encuentran los casos de las editoriales Barbarroja o García Hispán ${ }^{3}$. En aquella, de nombre significativo si atendemos a cómo denominaron los nazis la invasión a la URSS, han aparecido textos sobre la División Azul en tono complaciente o incluso alguno firmado por Leon Degrelle. En esta, "propiedad de un ex-militante de la organización neonazi CEDADE" (Núñez Seixas, 2005: 95), también se han repetido textos sobre la División de idénticas características. Como puede observarse, y para cerrar esta cuestión, nuestro camino se adscribe al iniciado por los cuatro primeros autores aquí tratados por las razones ya mostradas.

Para nuestro objeto de estudio es de mayor trascendencia la cuestión meramente literaria. Hemos señalado que, para Núñez Seixas, se trata de un subgénero dentro de la literatura fascista española. Entendemos esta como lo hizo en su día Julio Rodríguez Puértolas. Para este autor, entra dentro de dicha valoración "todo aquel que de un modo u otro puso su pluma y su pensamiento al servicio, con todos los matices que se quiera, del régimen político surgido de la sublevación militar contra la Segunda República española" y "a quienes antes de esa fecha formaban parte de las organizaciones que propugnaban la destrucción de la democracia y la creación de un Estado autoritario" e incluso "a quienes después de la muerte del general Franco el 20 de noviembre de 1975, o intentan un regreso al viejo sistema, o simplemente manifiestan una ideología antidemocrática" (2008: 7-8)4. A pesar de estar de acuerdo

\footnotetext{
Véase, para García Hispán, la colección dedicada en exclusiva a la División Azul en la que pueden hallarse los títulos como Breves notas sobre la División Azul (José Antonio Vidal y Gadea, 1991); La bolsa del Voljov (Juan Negreira, 1991); Berlín a vida o muerte (Miguel Ezquerra, 1999); División Azul: las "batallitas" de mi abuelo (Miguel Martínez-Mena, 1991); Generación puente (Manuel Álvarez de Sotomayor Gil de Montes, 1991); La Guardia Civil en la División Azul (José García Hispán, 1991); Impresiones: centinela junto al Ilmen (Ramón Farré Palaus, 1991) u Otra vez en Grafenwöhr (Pablo Castelo Villaoz, 1991). Y, para Barbarroja, cuyo nombre ya de por sí es significativo, el listado de títulos que ofrece su catálogo en relación con el revisionismo y la División Azul: A las órdenes de vuecencia: autobiografía del intérprete de los generales Muñoz Grandes y Esteban-Infantes (Juan Ackermann Hanisch, 1993); Los prisioneros de la División Azul: españoles en el Gulag (Fernando Vadillo, 1996); Historia de la división azul (Enrique de la Vega Viguera, 1999); El espíritu de la División Azul, Possad (José Viladot Fargas, 2000); Más que unas memorias, hasta Leningrado con la División Azul (Vicente Linares Fernández, 2000). A estos se unen los citados en la bibliografía Caballero e Ibáñez (1989). Por continuar este listado, pueden hallarse también títulos del ámbito internacional de la II Guerra Mundial como Mi camino de Santiago (Léon Degrelle, 1996) o Léon Degrelle y el rexismo (Léon Degrelle y Erik Norling, 2005).

4 Somos conocedores de las dificultades que encierra el término literatura fascista. Por ello, creemos conveniente rescatar lo que ha señalado Sultana Wahnón, quien ha indicado estar "muy lejos de establecer una identidad absoluta entre franquismo y fascismo" ya que solamente deben considerarse así "aquellos textos (y autores) que, en un momento determinado, asumieron y defendieron el corpus de ideas estéticas que el análisis nos han permitido identificar como tales" (1998: 9). Este es un debate que va más allá de la literatura y se extiende al estudio político del régimen. Ante tal irresolución se ha lamentado Ismael Saz Campos: "creo que, por mucho
} 
con ambas afirmaciones — subgénero y literatura fascista - , hemos de matizar que no todos los escritores que se acercaron a la División Azul pueden ser considerados como parte del entramado de la literatura fascista. Aunque veremos el corpus a continuación, especialmente en este trabajo puede observarse el caso de la nombrada Carmen Kurtz, quien estaría mucho más cercana a sus coetáneas Carmen Laforet, Carmen Martín Gaite o Ana María Matute que a autores como Alberto Crespo, José Luis Gómez Tello o incluso el propio Dionisio Ridruejo. En este sentido, cuesta identificar como escritores de la literatura fascista a autores como Tomás Salvador, Luis Romero o incluso Carlos María Ydígoras.

Aunque partimos de la noción del subgénero para clasificar los textos de la División Azul, quedarnos en este apunte crítico dejaría de lado a otros autores que han estudiado la literatura divisionaria. El mismo Rodríguez Puértolas ha destacado su "prosa directa, entre periodismo y crónica, y mínima preocupación estética, sustituida por la retórica del fascismo y por los habituales tópicos acerca de las virtudes de la raza hispánica" (2008: 714), cuestión con la que estamos de acuerdo. Del mismo modo, consideramos que debe ser tenido en cuenta lo que ha señalado José-Carlos Mainer, para quien "tienen un valor imperecedero que va más allá de la muestra de un estado de opinión precariamente adobado de literatura" (1989: 261). En cambio, no compartimos lo señalado por Caballero Jurado e Ibáñez Hernández, quienes consideran que las letras de la División Española de Voluntarios son, "en bastantes casos, de una gran calidad" (1989: 14). A pesar de su generosidad a la hora de realizar dicha calificación, es innegable que su monografía es el punto de partida para realizar cualquier tipo de estudio acerca de la literatura de la División Azul. Por lo tanto, cumplen con la labor que se propusieron en su día, ya que el libro "pretende ser únicamente una recopilación sistemática de material de trabajo para futuras investigaciones que, algún día, deberán llevarse a cabo" (1989: 9). Opuesto especialmente al de Rodríguez Puértolas es el trabajo de Francisco Javier González Martín, para quien este tipo de narrativa "no se trata de literatura fascista" (2015: 105), ya que entre estos escritores "no existe una intención propagandística de carácter ideológico, solo escriben sobre su experiencia personal" (2015: 117). Nosotros creemos que sí existe una voluntad propagandística de la misión divisionaria que, si no parte directamente de los autores, sí que lo hace al menos desde el poder estatal. Para ello, señalamos el ejemplo de la obra Ida y vuelta (Antonio José Hernández Navarro, 1946) y que volveremos a utilizar para justificar otro aspecto de este tipo de literatura. Consideramos que esta novela es un claro prototipo del ideal falangista que motivó la marcha de los voluntarios convencidos políticamente de la empresa de la División, ya que en ella no faltan referencias a la retórica falangista o incluso comentarios antisemitas (1971: 59,99). Dicho esto, debemos señalar que la obra tuvo problemas para ser publicada al ser rechazada en un primer momento por la censura debido a "motivos de oportunidad" (Archivo General de la Administración, caja 21/10709, exp. $n^{\circ} 2240$ ). Aunque la retención fue cuestión de meses, esta se explica por la difícil situación geopolítica del régimen tras el final de la II Guerra Mundial,

que nos empeñemos, no conseguiremos resolver el eterno debate acerca de si el franquismo fue autoritario o fascista, porque en ninguno de los dos supuestos conseguiremos captar la especificidad de la dictadura franquista: los elementos que le asemejan al fascismo lo diferencian nítidamente de las simples dictaduras de derecha o regímenes autoritarios; los que le distancian de aquél impiden su consideración como dictadura fascista" (2004: 90). Nosotros, sin ninguna pretensión de dilucidar el debate, utilizamos el término fascista para agrupar a los escritores afines al régimen, más allá de sus peculiaridades. 
lo que nos lleva a pensar que sí había una pretensión ideológica desde el poder hacia estos textos. Por último, Luis Negró Acedo ha afirmado que "amputados de la razón ideológica que podría haberlos estructurado, estos relatos se pierden en reiterativas descripciones de ataques y contraataques en un frente eternamente nevado" y que "separados artificialmente del contexto de la Segunda Guerra Mundial, los relatos se quedan en una serie de anécdotas muy poco significativas" (2008: 150). A pesar de que podríamos estar de acuerdo con la primera parte de la definición, no podemos más que refutar la segunda. Lo narrado por los combatientes, aunque se encuadre en el contexto de la participación de los españoles encuadrados en la Wehrmacht en la contienda internacional, no habla únicamente de ella. Por ejemplo, las alusiones a Franco son mínimas y si hay una figura recordada es la de José Antonio Primo de Rivera, de quien afirma Carlos María Ydígoras en su novela que si resucitara "la diñaría del susto. Limpiamos España de comunistas pero saldrán otros tan malos como ellos. Y más hipócritas" (1963: 54).

Nosotros consideramos que la literatura divisionaria durante el franquismo no fue abundante pero sí significativa, una afirmación que viene refrendada por el número de novelas y memorias existentes sobre la División Azul en relación a la participación de esta en la II Guerra Mundial: una unidad de aproximadamente cuarenta y cinco mil soldados en un único frente durante no más de dos años completos. Creemos que la considerable cifra de estudiantes universitarios y personas de alto nivel cultural entre los voluntarios influyó en la redacción de los textos. Pero, sobre todo, fue fundamental la necesidad de recordar su papel en la Unión Soviética, por lo que sus textos funcionan como un método de resistencia ante el uso a discreción de su memoria desde el gobierno. Por lo tanto, estas narraciones pueden ser consideradas típicamente fascistas pero no por ello adeptas al poder dictatorial. Los motivos políticos reivindicados, desde visiones falangistas y/o anticomunistas, se entremezclan con una nostalgia que convierte al infierno ruso en la huida de una realidad desalentadora.

Dicho esto, pasaremos a presentar e identificar el corpus de nuestro análisis. Al contrario de lo que pudiera pensarse, no todas las narraciones se ajustan al pacto autobiográfico que, según Philippe Lejeune, se trata de un relato "retrospectivo en prosa que una persona real hace de su propia existencia, poniendo énfasis en su vida individual y, en particular, en la historia de su personalidad" (1994: 50). Es decir, el lector asume la identificación del autor, el narrador y el personaje protagonista con la misma persona y, al mismo tiempo, lee los hechos como verdaderos (85). Varias de ellas son novelas que se identifican con el primer modelo de mundo (tipo I) de los tres que ha identificado Tomás Albaladejo en su texto Semántica de la narración: la ficción realista. Este es así descrito por el estudioso ${ }^{5}$ :

[Está] formado por instrucciones que corresponden a reglas propias de la realidad efectiva, por lo que en tal caso lo que hace es adoptar una sección de la propia realidad efectiva, de tal modo que como estructura de conjunto referencial depende de este modelo de mundo una serie de seres, estados, procesos, acciones e ideas

\footnotetext{
Los otros modelos propuestos por Tomás Albaladejo son, por un lado, el tipo II, que construye una serie de instrucciones que no pertenecen a la realidad efectiva, pero a la que son equivalentes, lo que define a un texto de este tipo como verosímil ficcional. Y, por otro lado, el tipo III, en el que las instrucciones construidas tampoco pertenecen a la realidad efectiva y, además, no guardan ninguna semejanza con esta, de ahí que un texto de este modelo sea considerado como inverosímil ficcional (1992: 53).
} 
que forman parte de esa realidad, pues están regidos por un modelo de mundo tomado de la misma. (...). Los de este tipo son modelos de mundo de lo verdadero (1992: 52-53).

El corpus seleccionado está compuesto por los siguientes quince títulos: De España a Rusia: 5.000 kms. con la División Azul (Víctor José Jiménez y Malo de Molina, 1943), ¡Guerra! Historia de Luis Pablos y El sol y la nieve (Rodrigo Royo, 1944 y 1956), De las memorias de un combatiente sentimental (Alberto Crespo, 1945), Canción de invierno en el Este. Crónicas de la División Azul (José Luis Gómez Tello, 1945), Ida y vuelta (Antonio José Hernández Navarro, 1946), 4 Infantes, 3 luceros (Jaime Farré Albiñana, 1949), División 250 (Tomás Salvador, 1954), Rusia no es cuestión de un día... Estampas de la División Azul (Juan Eugenio Blanco, 1954), La Rusia que yo conocí (Ángel Ruiz Ayúcar, 1954), El desconocido (Carmen Kurtz, 1956), Algunos no hemos muerto (Carlos María Ydígoras, 1957), Tudá (Allá) (Luis Romero, 1957), Orillas del Voljov (Fernando Vadillo, 1967), Cuando empuñamos las armas: la pequeña historia de una familia numerosa entre 1936 y 1942 (Alfonso de Urquijo, 1973) y Cuadernos de Rusia: diario 1941-1942 (Dionisio Ridruejo, 1978).

Antes de avanzar en nuestro trabajo, creemos necesario explicar dos puntos sobre esta selección: en primer lugar, debemos distinguir, en atención a lo señalado más arriba, entre memorias y novelas. Al primer grupo, es decir, el identificado con los postulados de Lejeune, pertenecen las narraciones de Jiménez y Malo de Molina, Gómez Tello, Blanco, Ruíz Ayúcar, Urquijo y Ridruejo. Y al segundo, el descrito por Albaladejo, las de Royo, Crespo — aunque aparezca la palabra "memorias" en el título, se trata de un relato ficcional—- Hernández Navarro, Farré Albiñana, Salvador, Kurtz, Ydígoras, Romero y Vadillo. Aunque en estas, con la excepción del caso de Carmen Kurtz, es innegable el poder que tiene la rememoración en su construcción, se trata de novelas entendidas según el esquema presentado por Albaladejo. Para ello, observamos brevemente el caso de Ida y vuelta. Al final de ella se afirma que la experiencia de la División Azul se trata de "una novela de recuerdos" (Hernández Navarro, 1971: 248). A pesar de este hecho, el personaje se llama Agustín y no Antonio José, como su autor, quien no nos pide que leamos su texto como unas memorias, sino como todo lo contrario. En el prólogo que escribió a la segunda edición, aparecida en 1954 e incluido en la edición que manejamos, señala que su libro "es la novela de mis camaradas" (1971: 18). Y en la introducción que incluyó en la primera edición, resalta que el protagonista podría "haberse llamado Pedro, Juan o Francisco" y que "es, por tanto, no un hombre determinado, sino un hombre cualquiera representante idóneo de una generación" (1971: 19). Es un texto que, como el resto de novelas, hace memoria pero debe ser leído como una ficción.

$\mathrm{Y}$, en segundo lugar, queremos aclarar el límite temporal utilizado, ya que puede resultar extraño que hayamos establecido el final del mismo en 1978, sobre todo si tenemos en cuenta que se han publicado novelas y memorias sobre la División Azul hasta nuestros días. Nosotros, en otro de nuestros trabajos (2016: 329-586), hemos realizado una distinción entre las obras literarias de la División Azul escritas durante la dictadura y el tiempo actual. Este hecho, avalado por la publicación de diferentes narraciones que, recientemente, han tomado a la unidad de voluntarios como tema principal o tangencial de las mismas, nos permite señalar que en ellas el discurso toma diferentes matices al sacar a la luz temas ocultos durante la dictadura. Al mismo tiempo, se alejan del tono glorificador que caracterizó a la mayoría de las escritas 
durante el franquismo. Respecto a esta división temporal, ampliamos en tres años el límite respecto al final de la tiranía franquista para dar cabida al texto de Dionisio Ridruejo. Publicado de manera póstuma, consideramos el texto del ideólogo falangista dentro de esta selección ya que ni él pudo retocarlo tras la muerte de Franco, ya que falleció cinco meses antes que él, ni esto sucedió después del periodo 1942-1943 y en la preparación de la edición de 1978 (Núñez Seixas, 2013: 22). Y, sobre todo, incluimos a Ridruejo en esta selección por su relevancia histórica y política que va más allá de la propia División y porque "los Cuadernos de Rusia merecen un puesto de honor en la amplísima literatura memorialística sobre la División Azul" debido a "su calidad literaria" (Núñez Seixas, 2013: 23).

\subsection{Mujer y División Azul}

Los divisionarios tuvieron trato, durante su experiencia, con dos tipos de mujeres: las españolas y las naturales de Alemania y la URSS. Por lo tanto, de estas relaciones dejaron testimonio en sus memorias y novelas. De su lectura y análisis se extrae la imagen de la mujer que proyectaron en dichas circunstancias. Al igual que realizaremos en la parte central del estudio, vemos necesario diferenciar a las compatriotas de los soldados de las que encontraron en tierra extraña, ya que el trato y la consideración que tuvieron con cada una de ellas fue diferente.

Nira Yuval-Davis (1996) ha estudiado el papel de la mujer a la hora de construir la nación. Para la estudiosa, ellas siempre han sido relegadas a un segundo nivel o, como mínimo, han sido las segundas en adquirir los derechos otorgados a los hombres. La ciudadanía, en su origen, se constituye en torno a los “'Derechos del Hombre', un contrato social fundado en la 'fraternidad de los hombres' (como reza uno de los eslóganes de los estados de la Revolución francesa y no por casualidad)" (1996: 167). Esto sucede en torno a la pertenencia a la colectividad nacional. En otro ámbito, destaca cómo es "frecuente que las mujeres simbolicen la colectividad nacional, sus raíces, su espíritu, su proyecto nacional" (170), lo que enlaza, inevitablemente, con la reproducción biológica que la nación exige: "El estímulo o el desaliento a las mujeres para que tengan hijos están determinados, en gran medida, por la situación histórica específica de la colectividad, y ni siquiera en las sociedades más permisivas existen como institución regida por el laissez faire" (172). Consideramos que estos factores se dieron en torno a la construcción la nación franquista: se fomentó una sociedad patriarcal en la que las afines a los postulados dictatoriales fueron consideradas como las dadoras de vástagos puros, lo que estuvo condicionado por el momento histórico concreto ${ }^{6}$.

La victoria en la Guerra Civil de los sublevados desactivó los logros y cambios sociales obtenidos durante la II República. El nuevo Estado relegó a las mujeres al hogar para que, desde allí, cumplieran con su papel como educadoras y transmisoras de los valores tradicionales, que permitían perpetuar la jerarquía y la autoridad de la dictadura a nivel social. La misión se hacía desde la casa para reparar los daños de la guerra y la postguerra a nivel poblacional - descenso de la población y altos niveles de mortalidad infantil - y desde ciertas profesiones recomendadas para las féminas (Rabazas Romero, Ramos Zamora, 2006: 46-48). Entre estas se encontraban la enfermería, la costura y la moda. Nosotros consideramos, para el caso de la

6 En otro de sus textos, la autora dice lo siguiente acerca de este tema: "La presión sobre las mujeres para que tengan más hijos puede ser también una estrategia nacionalista para superar un desastre nacional” (2004: 53). 
División Azul, a la primera únicamente como tal, ya que por las otras no se recibía ningún tipo de contribución económica y era un servicio que podía entrar dentro de las labores de las integrantes de la Sección Femenina y las publicaciones desde las que se solicitaba su colaboración.

El modelo de mujer proyectado por la Sección Femenina combinó la feminidad más tradicional con la implicación activa en el proyecto político del nuevo Estado (Blasco Herranz, 2014: 56). Las mujeres de la Falange, alejadas de cualquier posición feminista, ya que su papel siempre estaba subordinado al servilismo hacia el hombre (Gallego Méndez, 1983: 198), encontraron en la labor asistencial un modo de vida que respondía a los deseos de contribuir a la causa por parte de las más ideologizadas. El Auxilio Social colmó estas expectativas durante la postguerra (Cenarro Lagunas, 2010: 72) y en 1941 surgió la misma oportunidad que tuvieron los hombres para colaborar con el fascismo español. La formación de la División Azul requería el envío de enfermeras que atendieran a los soldados heridos en los hospitales de campaña, labor que cumplieron lejos de la primera línea de fuego pero sí con gran riesgo debido a los bombardeos a los que fueron sometidos, en diferentes ocasiones, los recintos con heridos españoles (Poyato Galán, 2015: 422). El llamamiento desde los diferentes medios del aparato dictatorial fue inminente, lo que requirió de esfuerzos propagandísticos que han sido señalados para varios medios de comunicación por Giménez Muñoz (2016: 274-278). Entre estos no se encuentran, curiosamente, las revistas femeninas de la Falange Medina e Y. Revista para la mujer. Especial es el caso de la segunda, ya que en ella a División "se convirtió en el tema más frecuente" entre 1941 y 1942 (Suárez Fernández, 1992: 141). Por lo tanto, no es raro leer en $Y$ testimonios de enfermeras que acudían convencidas a la URSS y a las que su padre habría alistado incluso en contra de su voluntad (Huecar, 1941: 48) o de soldados que, al regresar, confiesan que gracias a ellas han tenido "el consuelo de escuchar una voz de madre, de hermana y de novia al mismo tiempo" (Diego, 1942: 49) 7 . En todo caso, el movimiento de estas mujeres ha sido calificado como "la manifestación más pública de solidaridad con la División Azul" (Richmond, 2014: 147) por parte de la organización falangista femenina. Al igual que ocurrió con los varones, representaron en el mismo grado los problemas de compatibilidad existente entre los miembros del partido y del Ejército (Agustí Roca, 2003: 31; Negreira, 1991: 31). Falange quiso acaparar la actividad de las españolas en el frente. La Sección Femenina, en función de su antigüedad como grupo responsable de aquellas que cuidaron de los sublevados durante la Guerra Civil, organizó y envió, a las dos semanas de marchar los hombres al Este, el primer contingente para servir a los heridos. Primo de Rivera dispuso una clasificación en tres grupos a la hora de promover el reclutamiento de las falangistas interesadas: el primero estaba compuesto por veteranas de la lucha fratricida, el segundo por enfermeras del grupo que no hubieran participado en la contienda pero que sí eran tituladas y el tercero por chicas sin el título pero que demostrasen buena disposición para la misión encomendada. El monopolio de la hermana del Ausente se vio truncado cuando, en julio de 1941, fue creado por el Ejército el Cuerpo de Damas de Sanidad Militar, que tuvo bajo su mando a Mercedes Milá Nolla.

Este cuerpo lo constituyeron mujeres que, de forma totalmente altruista, trabajaban como enfermeras honoríficas sin sueldo. Para ingresar en el Cuerpo, realizaban un

Véase, para la representación de la División Azul en la revista $Y$, nuestro trabajo (Guzmán Mora, 2018). 
cursillo de dos años de duración en el que recibían clases técnicas de enfermería y conocimientos militares (incluidos instrucción en orden cerrado). Vestían uniforme militar: guerrera caqui, falda, gorro y bolso de costado, con el emblema de Sanidad Militar en la solapa. En los hospitales usaban el uniforme de enfermeras y durante las maniobras vestían traje de faena y botas igual que cualquier soldado (Gallardo Rodríguez, 2012: 161).

Medio año después, en enero de 1942, el enfrentamiento se avivó debido a la ley por la que se creó el Cuerpo de Enfermeras de FET y de las JONS, que atribuía a las mujeres azules, en caso de conflicto, la responsabilidad de aportar a las sanitarias. El Ejército hizo caso omiso a la nueva legislación y, a pesar de las protestas de la mandataria de la Sección Femenina, las cinco expediciones restantes se realizaron en conjunto con las militares y las que pertenecían a la Cruz Roja (Ruiz Franco, 2015: 38-44). Más allá de estos datos, gracias a ellas "los heridos españoles disfrutaron de las atenciones y cuidados casi maternales - muy de agradecer en esas especiales circunstancias - de las mujeres que, procedentes de las Milicias, el Ejército y la Cruz Roja, prestaron sus servicios en los hospitales españoles" al mismo tiempo que formaron una parte importante del "sistema sanitario propio que resultó trascendental para atender en tierra extraña a los heridos y enfermos en combate" (Ibáñez Hernández, 1996: 67).

Las que no fueron hasta el frente del Este ejercieron desde España como madrinas de guerra. Ellas respondían a las cartas de los hombres que, según la escritora Dulce Chacón, escribían "cuando el espanto duerme, por un rato, y aflora la necesidad de compartir el desasosiego" (Chacón, 2003: 19). Su función no comenzó hasta el verano de 1942, cuando Pilar Primo de Rivera solicitó a sus delegadas provinciales la búsqueda de doscientas muchachas adecuadas, por su fidelidad a la causa, para que escribieran misivas al menos a uno o dos soldados. Los aludidos tuvieron conocimiento de la iniciativa a través de su publicación interna, la Hoja de campaña, y se les distinguía por llevar prendido un distintivo en la prenda falangista conocido como "el parche de la madrina de la División Azul". Además de españolas, a estas mujeres se unieron alemanas, italianas, francesas y, sorprendentemente, japonesas. De todas ellas, la más famosa fue Celia Giménez Costeira, conocida como la madrina de la División y que cada miércoles, desde 1941, emitía un programa de una hora en Radio Berlín en el que

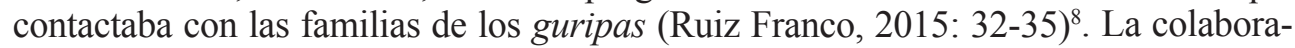
ción de las mujeres falangistas, mediante cualquier tarea, fue amplia:

Las mujeres falangistas de la Sección Femenina (SF) se sumaron desde un principio a la iniciativa de sus correligionarios varones y tuvieron una destacada participación en diversos ámbitos como el de enfermeras en el frente, lavaderos, donación de sangre o con diferentes colaboraciones en la retaguardia desde madrinas de guerra o labores de intendencia como la organización de donativos para los soldados y sus familias o recogida de ropa y alimentos (Ruiz Franco, 2015: 20).

Guripas era como se llamaban a sí mismos los divisionarios dentro de una rica jerga que puede apreciarse en las novelas y memorias, en la que destacan los términos doiches — alemanes_, ruskis — rusos-y panienkas o pañenkas - mujeres soviéticas de la retaguardia_- Un perfil sobre Celia Giménez Costeira lo ha ofrecido Bowen (2000: 86). 
Fuera de España, los combatientes conocieron a mujeres alemanas y rusas, con las que se abrió un mundo nuevo que difería del trato con el prototipo de fémina promulgado por el franquismo. Con ellas, los españoles pusieron en práctica el donjuanismo divisionario. Según esto, los españoles habrían tenido, como reconocía una enfermera española, una "docena de novias" (Diego, 1942: 13). Ellos mismos presumían de realizar la corte a las mujeres de los lugares que habitaban, ya que huían cada noche para "hacer de donjuanes con las jóvenes campesinas de rostro ovalado y cabellos claros y voz melosa y aterciopelada" (Vadillo, 1967: 176). En el campamento militar de Grafenwöhr, en Baviera, tuvieron contacto con las alemanas. Allí "deberían respeto a las mujeres que regentaban las cantinas, esposas de combatientes" (Moreno Juliá, 2005: 123), a pesar de lo cual "unos cuantos soldados se saltan la disciplina militar, con la complicidad o no del personal de guardia, para hacer un recorrido nocturno por los pueblos de los alrededores, de cervecería en cervecería, y probar suerte con las alemanas" (Rodríguez Jiménez, 2007: 93). En relación con la moral del nuevo Estado puede imaginarse la torpeza de estos chicos, "que sabían poco de cuestiones sexuales y que casi ninguno había visto ni sabía lo que era un dispositivo para evitar un embarazo no deseado", a quienes "sorprende el reparto de preservativos por la intendencia alemana y la posibilidad de comprarlos en máquinas expendedoras instaladas en tabernas y otros establecimientos" (Rodríguez Jiménez, 2007: 93-94). Los acercamientos entre ambos sexos se produjeron y "pese a que muchos de los éxitos que los divisionarios dicen haber cosechado con las chicas alemanas parecen excesivos (...) es seguro que algunos se echaron novia y que otros disfrutaron de encuentros sexuales esporádicos" (94). Esta indisciplina provocó la publicación de una Hoja de instrucción para los soldados españoles por parte de las autoridades locales en la que "[se] advierte a la tropa de que las chicas alemanas tienen prohibido estar en la calle sin ser acompañadas por su padres o personas autorizadas después de las nueve de la noche, y que la policía asume el control correspondiente" (94). Ante tal restricción en el horario de salida de las germanas los azules, entre quienes habían perdido la inocencia y los que llegaban resabiados desde España, "dirigieron la vista hacia las mujeres polacas que eran empleadas como mano de obra esclava, a las que habían visto trabajando en la calle bajo vigilancia militar y cuyos barracones estaban situados en las inmediaciones del campamento" (95). La prohibición se amplió al abarcar a las prisioneras, orden a la que hicieron caso omiso a sabiendas que a estas mujeres "se [las] puede comprar por un poco de comida" (Reverte, 2011: 101). Cabe decir que "los malnacidos que practican ese comercio son pocos (...) [a pesar de que] alardean de sus conquistas en las tertulias de barracón que preceden a la entrega al sueño" (Reverte, 2011: 101).

Las relaciones con las rusas, a las que se denominó con la palabra polaca pañenka - a veces también panieka - tomaron la misma dirección que las mantenidas con las germanas. Los divisionarios vivieron algunas relaciones de amor, a pesar de la prohibición española de las mismas, que pedía el idéntico respeto que se exigió por parte de los alemanes durante la instrucción. Como se contemplará, su descripción en comparativa con las camareras y pobladoras de Grafenwöhr es negativa pero, para muchos de ellos, igualmente idílica. Al mismo tiempo que se desarrollan estos fugaces noviazgos, se repiten las escenas de prostitución acuciadas por la necesidad alimentaria de las indígenas, como había ocurrido anteriormente con las cautivas polacas (Núñez Seixas, 2016: 278-283). Y, más allá de las trincheras, cuando los españoles acudieron al Este descubrieron, mientras convalecían de sus heridas, la 
tranquilidad de la Riga ocupada. Allí, al mismo tiempo que se recuperaban y frecuentaban los cafés de la ciudad, alejados del terror de la guerra, tuvieron sus novias pasajeras. De estos casos, al menos el del soldado toledano Vicente Martínez de Cepeda Galán finalizó en boda (López-Covarrubias, 2012: 319-324).

\section{La imagen de la mujer en la narrativa divisionaria}

Como hemos anunciado, nuestro análisis se dispone en torno a tres motivos: la representación de las mujeres españolas, las alemanas y soviéticas y el acercamiento a la novela El desconocido. Con ello, creemos cubrir todas las representaciones posibles femeninas al mismo tiempo que contemplamos la escritura de ellos - los divisionarios-y a Carmen Kurtz, la única mujer que se acercó al tema.

\subsection{Madrinas de guerra y enfermeras: las españolas}

Como se ha indicado arriba, los voluntarios tratan con dos tipos de mujeres españolas durante su experiencia en la II Guerra Mundial según por la cercanía o la lejanía geográfica establecida entre ellas y ellos. Por un lado están las que moran en España - las novias, las esposas y, sobre todo, las madrinas de guerra - y, por el otro, las enfermeras de la Falange y del Ejército. A los soldados en España les esperaba con frecuencia una mujer que, nada más partir hacia el Este, es olvidada a propósito para que no interfiera en las correrías con las nativas de los diferentes países a los que acude. Aun así, en determinados momentos aparece la imagen de esta mujer que representa los valores de la chica casta, paciente y católica del franquismo. El divisionario, a pesar de conocer a otras, regresa a ella en sus pensamientos, como le ocurre a Agustín, el protagonista de Ida y vuelta. Él, que se pregunta cómo puede ser comunista una mujer rusa "con unos ojos magníficos de una dulzura casi sobrehumana" (Hernández Navarro, 1971: 135), que conoce a "Alina, de pelo castaño y ojos verdes, esbelta y ardorosa, que no sabía besar sin morder hasta hacer sangre" (224), o que tiene un amorío con Annelies durante la instrucción en Alemania, una "muchacha que aún no había olvidado, pero de la que sólo quedaba en su corazón una leve sombra" (228), se decanta finalmente por Asunción, su enamorada de España: "Y al anochecer, ya solo, Agustín, soldado en Rusia, se sintió colegial y hasta la hora de la cena soñó un mar de deleites imaginando rozar, con su mano áspera de combatiente, los finos y tibios dedos de Asunción" (174). A la par, este anhelo toma tinte medieval cuando acude al combate: "Al tiempo de persignarse y de pisar la nieve, pensó que era muy de novela el salir a una operación dejando una carta incompleta par la mujer amada; una carta que podía quedarse para siempre sin escribir" (179).

Además de esta situación, en el caso divisionario cabe resaltar, por su protagonismo, la relación epistolar entre los combatientes y las madrinas de guerra. Aunque parezca que estos hidalgos del siglo XX buscan un provecho material de ellas, en la literatura son capaces de situarlas en un lugar más alto que a las mujer extranjeras con las que tienen aventuras esporádicas: "Pensé en los ojos verdes de Lora, y la imagen de mi madrina de guerra española se superpuso a la visión de la rusa" (Jiménez y Malo de Molina, 1943: 118). Pero, en algunos momentos, la caradura del divisionario sale a relucir cuando uno de ellos se cuestiona si retomar la relación con 
su novia o ir a conocer a la que había atenuado los efectos de la batalla con sus palabras: "Mi madrina es maravillosa. También mi novia. Una es de Burgos, y la otra, de Madrid; ¿qué os parece? Las dos esperan mi vuelta..., ¡vaya! tendré que echarlo a cara o cruz. Será lo mejor" (Crespo, 1945: 144).

Las jóvenes españolas representan la inocencia que no encuentran más allá de los Pirineos. Quien mantiene una relación más intensa con su madrina es el soldado del texto de Farré Albiñana. Tras un breve regreso se encuentra con ella y recuerda la vez anterior que se habían visto, cuando la chica, tras desdoblar "la mantilla, y enredando tu cabello en la malla, te adentraste en la iglesia" (1949: 37). Ella muestra una actitud infantil al tratar con especial cariño a un juguete que él le había regalado al volver del frente, un bebé de paseo al que bautiza como "nuestro peque" (34), al que arrulla "cada noche" y sobre el que llega a cuestionar al protagonista sobre si "un día nos llev[ar]emos el muñeco de paseo" (94). Lo narrado anteriormente en combinación con la beatería de la muchacha le lleva a prometer al divisionario que, en la "vigilia de mi marcha sacaremos "nuestro peque' a paseo y vendremos a rezar el rosario" (123). De hecho esto sucede y a él le "sorprende y alegra que en el reclinatorio se nos interponga 'nuestro peque'. Está arrodillado y con las manos juntas; como si rezase" (225). Y, por estas razones, más que con una mujer joven, el guripa tiene la sensación de tratar con una niña, algo que él intuía, ya que estaba "seguro de que no sabes [besar]" (210). Cuando él le pide a ella que le hable de su niñez, se comprueba que no existe tanta diferencia entre el estilo de vida anterior y el presente:

No se me ocurre nada. ¿Qué tonta soy, verdad?... Pero sí: de pequeña me gustaba mucho andar con muñecos; hacer de Mamá, ¿sabes? ¡Me ponían tan contenta esos juguetes!... ¡Tenía uno más mono! con una capita blanca... Lo mecía y le cantaba; y llegaba a creer que era de verdad. Se lo dejé a una amiguita y al caérsele me eché a llorar. Por la noche, al acostarme, me arrodillé junto a la cama y di un beso al Niño Jesús (1949: 210).

Para finalizar con el episodio de las madrinas, también puede leerse una descripción de la que todos compartieron, es decir, de Celia Giménez — en el párrafo ofrecido a continuación transcrito su apellido como Jiménez-. Curiosamente, a pesar de su intensa tarea, la imagen que se ofrece de ella es peyorativa:

Patrocinaba y dirigía personalmente las emisiones emitidas en castellano en Alemania una viuda de un militar, rubia platino, llamada Celia Jiménez, a la que yo había visto una vez en Grafenwöhr. Pretendía, con buena voluntad, llevar un poco de alegría a las familias de los voluntarios, dando noticias directas, que de esta forma podían llegar con mayor rapidez que por correo. La oíamos algunas veces, y el tono de su voz no nos resultaba agradable, y su forma de hablar nos parecía insoportable. El coronel Rodrigo, durante una visita que hizo a Berlín, fue requerido para que dijera algo por la radio, y se confundió, llamando a la locutora Celia Gámez en vez de Jiménez (Urquijo, 1973: 309).

Más escasas son las descripciones de las enfermeras que cuidaron de los españoles, quienes aparecen reflejadas durante la estancia de los soldados en los hospitales. En este sentido, se cumple lo que también sucede con este grupo, según Iker González-Allende, en la narrativa de la Guerra Civil, "lo cual es indicativo del papel 
secundario que se le asigna a la mujer en momentos de crisis nacional y, en general, en las teorizaciones de los nacionalismos" (2011: 125). La principal tarea de ellas era "la de atender a los hombres de la nación, en su caso a los heridos, con valores tales como la abnegación y la entrega desinteresada. Con su cuidado maternal, la enfermera consigue que la masculinidad infantilizada del soldado herido se vaya encauzando de nuevo hacia una masculinidad normativa y militar" (233-234). Como ha señalado este autor, el tema de la enfermera no fue muy tratado en la narrativa de la lucha fratricida, pero "durante la participación española en la Segunda Guerra Mundial con la División Azul (1941-43) en apoyo a Alemania, la enfermera volvió a adquirir protagonismo" (234). Nosotros creemos que la presencia de las sanitarias fue mayor en la propaganda estatal — como vimos arriba mediante dos ejemplosque en el mundo literario. Aun así, pueden contemplarse varios casos.

Ridruejo rememora a unas hermanas españolas entregadas a la causa falangista que ejercieron en Riga, de las cuales "una de ellas [es] muy guapa" (Ridruejo, 2013: 358). Las mujeres del personal sanitario para Fernando Vadillo son "unas enfermeras algo envaradas y como distantes dentro de sus uniformes" (Vadillo, 1967: 783), ya que ellas no intiman de ningún modo con los heridos, algo de lo que se lamenta el soldado: “¡Con las ganas que tenían ellos de charlar, aunque sólo fuera charlar, con una chica española!” (784). En cambio, Juan Eugenio Blanco no resalta la falta de reciprocidad en las intenciones de los voluntarios y sí la labor que realizan con ellos:

En el hospital, por primera vez en mucho tiempo, se podía hablar en español con alguna mujer, cosa que el que más y el que menos había pensado muchas veces que quizá no volvería a hacer. Nuestras enfermeras, casi todas ellas veteranas en la Cruzada, revalidaron en la campaña de la División Azul sus dotes de abnegación, simpatía y competencia (1954: 55).

Y Antonio José Hernández Navarro se detiene más que sus compañeros en hablar de las mujeres españolas a las que conoce durante su convalecencia. Recuerda a tres chicas que "nos tratan con mucho mimo, pero no las veo con toda la frecuencia que quisiera; las pobres chicas se pasan todo el día de un lado a otro (...) pues los heridos siguen llegando sin cesar" (1971: 128). Para él sí que hay un mayor nivel de intimidad, ya que una de ellas, cuya voz "es cálida y redonda como un desnudo de Julio Romero de Torres", entretiene a los soldados "cantándonos asturianadas" (132). Incluso se deleita al contemplar a otra, "tan bonita con la última luz del sol en la melena rubia y suave; su voz era tan armoniosa, que he estado a punto de claudicar" (137). De ellas deja una estampa descriptiva general:

No hay enfermera fija. La que más aparece por aquí es una chica de la Falange de Oviedo, que se llama Lola. No es guapa, pero tiene unos ojos grandes y negros inmejorables, y un tipo espléndido. Vienen dos más. Lucía y Margarita; las dos son bastante guapas. Lucía me recuerda a Asunción; tiene los ojos igual que ella, pero menos bonitos. Claro está que a Asunción me la recuerdan todas las cosas bonitas que me rodean, que no son muchas (1971: 128).

\subsection{Fräulein y pañenkas: las alemanas y las soviéticas}


La otra mujer con la que trata el divisionario es la indígena de los lugares en los que la expedición se encuentra en cada momento. Alemania supone el primer impacto en el contacto con el sexo opuesto, lo que se observa en atención al relato que los voluntarios han legado. Para Luis Romero, su mundo femenino de los meses de guerra se reduce "a las elementales palabras cambiadas con las chicas alemanas de las estaciones, de las cantinas, de las cervecerías de Grafenwöhr, a cuyo galanteo, por pereza, timidez o indiferencia, había rehusado, al verlas tan torpemente solicitadas por los bulliciosos grupos que formaban los compañeros" (1957: 123). Esta imagen, en la que se delega la responsabilidad de estas actividades en los camaradas, no es tan habitual como aquella en la que el soldado interviene de manera directa: "En algunas estaciones [de Alemania, camino a Rusia] hacíamos alto. Allí nos esperaban (...) muchachas de ojos azules y mirada soñadora. Las hablábamos, las besábamos cuando podíamos, y así nos llevábamos un recuerdo más" (Ydígoras, 1963: 49). Los divisionarios destacan, entre todas las experiencias amorosas que ofrecía la guerra, la vivida en el país germano:

Yo sé lo que es el amor en Riga, sobre las nieves boyardas de la Perspectiva, y hasta el amor en Estonia, confortablemente envuelto en abrigo de pieles. Pero estoy seguro de algo: si todos los géneros de amor desaparecieran repentinamente de la tierra, sólo dos sobrevivirían: el amor español, primero, y el amor en Baviera, después. Porque dentro de mil años, Don Juan seguirá raptando a las mocitas sevillanas, y dentro de mil años habrá una pareja silenciosa acodada en un puente de Baviera, mirando el agua pasar (Gómez Tello, 1945: 19).

Ridruejo se reviste de puritano y se muestra crítico con la actitud de sus compañeros cuando estos hablaban con las jóvenes alemanas. Lo sorprendente de sus palabras es que no responden a sus actos ya que protagonizó una aventura con una de ellas'

Estas gentes alemanas de los pequeños pueblos no pierden, ni en la aglomeración, esa especie de mansedumbre hogareña que a veces hace un poco demasiado gordas a las mujeres. Desde las ventanas - al paso por cualquier sitio - nos saludan también y agitan lienzos. Entre los divisionarios empieza a manifestarse esa detestable propensión al donjuanismo de ocasión que casi todas las agrupaciones de varios errantes - pero ninguna como las de españoles - propenden a manifestar. La estúpida leyenda de que el español tiene un éxito especial en la galantería en medios nórdicos gracias a su mucho temperamento (concepto zafio y deprimente si los hay y grosero como ninguno) empieza a hacer estragos (2013: 64-65).

Más allá de las nulas habilidades de algunos guripas con las enfermeras macionalsocialistas mientras permanecían heridos, a las que enseñaban a decir barbaridades como "Ich [bin] cachonda und tiabuena" (Farré Albiñaña, 1949: 188), con las alemanas tuvieron contacto casi de manera exclusiva en Grafenwöhr. Según narra Rodrigo Royo, allí "los soldados de aquella División, mucho más intelectual que

9 Se detecta cierta hipocresía en Ridruejo si se atiende a lo que han apuntado Gracia (2008: 26 y 82) y Rey-Ximena (2009) acerca de la relación que mantuvo el poeta falangista con una mujer a la que apodaban Hexe - Bruja en alemán-, una espía del nacionalsocialismo que estuvo en España. Incluso él mismo confiesa en su texto, tras una cita con ella, que "hubiera sido indecoroso no besarla apasionadamente al dejarla en su casa" (2013: 374). 
militar, no pensaban por entonces más que en representar a lo vivo algún romance pastoril con las sabrosas campesinas bávaras de piel manzana" (1957: 265). Este mismo autor, en el primero de sus textos divisionarios, se hace eco del amor de Luis Pablos con Hilde, a la que conoce un "día en que iba yo arrebolado por las intenciones más pecaminosas" (1944: 50). Ella, que "era hermosa como una noche rusa", le sirve para señalar las diferencias entre estas mujeres y las españolas, ya que mientras la alemana "parecía corresponderme", las chicas a las que él había conocido hasta la fecha dedicaban su vida en los momentos previos del matrimonio a "dos menesteres: la mitad, en aprender el modo de ocultar sus sentimientos; y la otra mitad, hacer creer que no salen de casa" (1944: 54). La relación entre estos dos personajes toma un tinte bucólico, puesto que el personaje se "creía un marqués pastor, diciendo madrigales a una duquesa labradora, como en tiempos de las églogas" (1944: 58). El contacto entre ellos no va "nunca [más allá] de aquellas demostraciones inocentes" (1944: 60), no como le sucede a otro de sus compañeros: "Ortiz sí que se divirtió de otro modo, según nos dijo, pero esto no hace al caso" (1944: 61). Durante la instrucción son frecuentes las descripciones de escapadas con estas eventuales novias:

[L]os que se perdían en las románticas colinas que rodeaban al Grafenwöhr, de la mano de las Helga, las Anna, las Greta o las Kari de las rubias trenzas a quienes les gustaba a rabiar el "viel temperament" de aquellos soldados extranjeros, turbulentos, vociferadores, que armaban la marimorena en las cantinas por un quítame de ahí esa paja, y que se comportaban melosamente con las chicas bávaras, acariciándolas, besuqueándolas, $\mathrm{y}$, a veces, coronándolas de flores silvestres a la hora en que el sol se hundía por el lado de España (Vadillo, 1967: 87).

El contacto con las prisioneras polacas, ya señalado más arriba, es un tema silenciado por la mayoría del grupo. Entre ellos, es Urquijo quien alza la voz para dar noticia de ellas - pero no de las visitas que recibían por parte de los españoles - y de su situación al mismo tiempo que se lamenta por su futuro ${ }^{10}$ :

Nuestro campamento estaba rodeado de inmensos bosques. Teníamos bastante cerca un campo de trabajadoras civiles polacas, totalmente incomunicadas, lo que nos hizo suponer que no eran voluntarias, sino desplazadas a la fuerza. Las veíamos pasar a veces en camiones, cuando las llevaban a trabajar en las carreteras, y en el trayecto iban cantando largas canciones melancólicas. Entre ellas había bastantes que eran francamente guapas. Su tragedia me pareció espantosa: desplazadas, aisladas de los suyos y de su país y obligadas a trabajos forzados. ¿Cuál sería el destino de aquellas pobres mujeres? (1973: 254-255).

Tras la despedida de la instrucción y la salida de Alemania, el soldado pasa a relacionarse con las mujeres de las aldeas polacas y soviéticas. La imagen que se ofrece de estas difiere un tanto de las que dejaron atrás. Aunque cambia el escenario, las prácticas de los soldados y la incidencia en el éxito que obtienen en los relatos son similares. A pesar de esto, sí es cierto que se aprecian algunas escenas imposibles en el territorio del Tercer Reich. El mismo Urquijo se refiere a una situación en la

10 Grandes (2015: 458-465) ha recuperado el aprovechamiento, por parte de los españoles, de las necesidades de las prisioneras polacas de Grafenwöhr en una de sus novelas. 
que un español, enamorado de la hija del alcalde de uno de los pueblos que habitan, está cerca de casarse con ella. Lo hilarante es la creencia del divisionario, para quien casarse durante la guerra es un pasatiempo exento de validez:

La familia de la barachina accedió [al matrimonio], y un buen día empezaron a celebrar en presencia de un pope la ceremonia nupcial ortodoxa, interrumpida por uno de nuestros oficiales, al darse cuenta de que el novio era uno de sus soldados. Dirigiéndose a él le dijo:

-Pero, ipedazo de animal!, ¿no sabes que los sacramentos entre rusos nos obligan también a nosotros?-A lo que el guripa contestó más fresco que una lechuga: Mi teniente, yo creí que esta boda no me valía. - Pero el caso es que le valió un buen arresto, y lo enviaron a España a que lo cumpliera (1973: 310).

En algunos relatos más planos, como el de Ruiz Ayúcar, el trato con la rusa se limita a la aceptación de un piropo: "La muchacha rio alegre ante aquel homenaje ruidoso y ardiente, como quizá nunca se oyera antes en la milenaria Rusia, y agitó una mano en el aire, en correspondencia maravillosa" (1954: 40). También atribuye características positivas a la mujer local al afirmar que, "en general, la campesina rusa es tan honesta como en cualquier otro país y más que en muchos" (103), lo que contrasta con Sofía, un personaje de sus cuentos. Ella, una mujer casada, "era una aventura de guerra; una aventura fácil por los síntomas. Y él disponía de meses para estar a su lado, mientras yo sólo podría verla unas horas y... quizá fueran sus ojos los últimos con que me mirara una mujer" (144). Pero el contacto esporádico se torna en decepción. En este caso, ella se revela como una mujer al servicio del Ejército rojo y desde esta perspectiva se la presenta dispuesta a cualquier acto - incluso inmoral para la España del momento- para lograr sus objetivos. Al ser descubierta recibe el castigo que tal condición estipula: "Esta mañana han fusilado a Sofía. Era una espía roja" (148).

Otras relaciones se inscriben en una vertiente lírica por la que el soldado confiesa sus sentimientos al afirmar que "estaba un poco enamorado de Nina: de sus ojos, de sus manos, de su boca y de su cuerpo, que adivinaba esbelto como un junco", una mujer casada cuyo "marido [que servía] en la aviación roja, conocía perfectamente la literatura rusa y las andanzas de la 'Pasionaria', por la que sentía una gran admiración" (Crespo, 1945: 47):

Cuando terminé de partir el tronco, fui hasta ella. Estaba apoyada en los travesaños de una escalera, con la cabeza echada hacia atrás. Entre el vestido y el nudo del pañuelo se le veía la garganta estirada, fresca, tersa, de una calidad mate como la de los pétalos de las flores. ¡Qué admirable contemplación para un soldado imaginativo! Debía ser tan suave aquella piel, donde no se veían siquiera las rameadas venitas azules, que al ponerme al lado de Nina sólo sentí deseos de acariciarla. Ella debió notar mi admiración, porque movió la cabeza y se quedó mirándome fijamente mientras rodeaba su cuello con una especie de toquilla que antes le colgaba de los hombros. Aquello hizo que me ruborizase, como lo hago siempre al notar que me han adivinado un pensamiento. Cuando recuerdo el gesto de Nina en aquellos momentos, ya bastante lejanos, me invade tal desasosiego, que tengo que volver la cabeza hacia el sitio donde sea mayor la soledad (Crespo, 1945: 56-57). 
También se da la situación en la que el divisionario se queda parado ante la belleza de la rusa y prefiere no actuar: "Servíanos una muchacha sonrosada y rubia, de ojos azules muy claros, que sonreía por cualquier motivo. Pensábamos todos que sería más fácil alcanzar su corazón que las murallas del Kremlin, pero no nos atrevimos a intentarlo" (Crespo, 1945: 56). En otras ocasiones la imposibilidad de la relación aparece por el miedo a que ella, al quedar embarazada, sea represaliada en un futuro, ya que "[s]i los bolcheviques volvían un día y la encontraban con un hijo, la matarían. Y nosotros no podíamos ofrecerle la seguridad de que los bolcheviques no volverían. Solo los vencedores tienen derecho a tener hijos con las vencidas" (Salvador, 1970: 220-221). En el comentario final queda latente el concepto que algunos soldados tienen de la mujer en la guerra, al deshumanizarla y convertirla en un trofeo que conquistar.

En una línea diferente y, casi inédita, Carlos María Ydígoras resalta algunas escenas grotescas en las que precisamente la característica principal es la ausencia de amor. En una de ellas describe a un grupo de soldados españoles entre quienes "había una muchacha... Aquella desgraciada se estaba entregando a los soldados, iba siendo poseída por los congelados y los heridos, por... Era grotesco, espantoso" (1963: 138). Incluso se atreve a narrar una escena que lleva a pocos equívocos si se interpreta como una violación, lo que se corresponde con lo que ha afirmado Nira Yuval-Davis sobre las dificultades de la población que se encuentra en la retaguardia, especialmente cuando se es mujer: "Las mujeres dejadas allí [en el frente interno, en la aldea] se vuelven vulnerables a violaciones de parte del soldado enemigo" (2004: 162). Uno de los divisionarios de la novela de Ydígoras hace una prisionera en una emboscada al recuperar el cadáver de un compañero. Cuando se dispone a regresar a la aldea con el fenecido y la rea, despiertan los instintos más bajos del divisionario, que son definidos como esa "atracción, absurda en tales momentos, [que] iba naciendo en mí" y que le lleva a introducir "mis dedos", acariciar "una suave tela" y subir "hasta encontrar la protuberancia de un pecho" (1963: 251). La imagen que sigue a continuación muestra con todo detalle la violencia sexual hacia la rusa:

Abrí por completo la guerrera del oficial para acariciar sus pechos ya casi libres; busqué su boca y, en ella encontré unos dientes que el deseo o el miedo clavaron en mis labios. Le pasé el brazo por la espalda, me pasó el brazo por la nuca. Sentí el contacto de unos pantalones llenos de fango endurecido; luego el de unos muslos, llegué hasta donde los mulos terminan. La muchacha murmuraba algo que jamás llegaría a traducir. Sus besos iban adquiriendo extraña pasión. Quizá queriendo encontrar en aquellas caricias la salvación, los dedos de la teniente recorrían mis cabellos, las mejillas, mis hombros... Su mano cayó bruscamente a tierra y mi mano, como movida por un relámpago, lo hizo sobre la suya (1963: 251-252).

Como puede denotarse en la descripción ya hay cierta intención de humillación al resaltar el autor la palabra oficial y muy poca de ocultar el forzamiento de la presa. Aunque el relato podría finalizar aquí, posteriormente ambos vuelven a encontrarse en dos ocasiones y, para ya alcanzar el mayor grado de paroxismo posible, ella se acerca al divisionario para agradecerle que viviera — en rudo español— "i[s]ólo porque tú no querer [sic] matarme!", a lo que el soldado responde: "Hombre..., si llego a querer..." (1963: 281). La rusa es integrada en el servicio español como traductora y encuentra un novio "alférez y creo que un día casarnos [sic]" (1963: 281), lo que no deja de extrañar 
al soldado quien, tras mostrar su alegría por reencontrarse con ella, declara sentirse "un poco padre tuyo" (282). En la última oportunidad en la que coincide con la muchacha, esta había perdido a su novio en combate y, debido a las necesidades que pasa, ejerce la prostitución. Al invitarla el español a ir con ellos, le dice lo siguiente: "Tú verás lo que piensas y lo que eres. Allí hay soldados. Si quieres, te ganarás uno marcos, y si no, te trataremos como Agustina de Aragón" (391). El final de la chica delata cómo no debería estar tan agradecida al español. Las escenas de prostitución, pagadas con productos alimenticios, no son muy abundantes, pero sí que se describe al menos un caso de manera negativa: "Son todas unas puercas, más feas que mi padre, y lo único que te pueden dar son ladillas, como no sea que te peguen unas purgaciones. Se están muriendo de hambre más que nosotros, no te creas que es mentira, que si quieres hacer algo con una panienka, te cuesta media ración de pan" (Royo, 1957: 125).

Cabe señalar que las soviéticas no fueron siempre idealizadas por los soldados españoles. Ellos, a pesar de descubrir en la URSS a los verdaderos rusos, cuya imagen distaba de la que la dictadura les había ofrecido, y de vivir aventuras amorosas con estas mujeres, las observaron en diversas ocasiones como seres inferiores a las alemanas ${ }^{11}$. La fémina rusa estaba destinada, en gran parte, a apagar la necesidad sexual del momento, hecho que no ocurría con la fräulein del tiempo de instrucción. Al fin y al cabo, el escritor azul descarga esta concepción de la misma, según su óptica, en el culpable del resto de los males del pueblo ruso, el comunismo. Este les habría robado su feminidad al igualarla en derechos y obligaciones con el hombre, lo que la despojaba de cualquier rastro de belleza:

En estas campesinas deformadas por el "stajanovismo" más inhumano es difícil reconocer mujeres. Les estalla en la boca, sin dientes o con dentadura de metal, una risa animal cuando se les apunta con la máquina fotográfica. $\mathrm{Y}$ da miedo pensar qué es lo que tiene por alma. Acaricia con sus manos de bestia y los ojos lejanos, intuyendo, tal vez, en sabe Dios qué honduras abismales del ser, que son mujeres. Que fueron mujeres. El soviet las entregó al tractor y al trabajo del campo sin limitación de jornada (...) No se puede llegar impunemente tan cerca de la bestia como lo ha hecho el comunismo con ciento setenta millones de seres humanos (Gómez Tello, 1945: 43).

\subsection{La óptica femenina: El desconocido (Carmen Kurtz, 1956)}

El análisis quedaría incompleto sin un acercamiento, aunque sea breve, a El desconocido (1956), de Carmen Kurtz (1911-1999) una escritora sin filiación a la División Azul $^{12}$. Esta obra por la que ganó el Premio Planeta se publicó pocos años después de

11 Núñez Seixas (2010) ha desarrollado con acierto la evolución en el tiempo de la percepción que tuvieron los divisionarios sobre Rusia y el pueblo ruso, que pasó del mayor de los odios incubado en España — que se conservó para el sistema político — al aprecio por sus gentes y sus tierras. El buen trato que dispensaron en general hacia la población es uno de los elementos de la literatura divisionaria. Este acuerdo total, que podría parecer impostado, ha sido corroborado por el desertor de la unidad César Ástor, quien, "a pesar de su rechazo del franquismo y de la División Azul, (...) reitera que los divisionarios se portaron de forma admirable con la población civil rusa, con la que incluso compartían la comida". Entrevistado por Arasa (2005: 330).

12 López Pavia (2007) ha publicado una interesante semblanza de la autora en La Vanguardia que, sintetizada, recoge su vida profesional y personal. De larga trayectoria, en 1911 vino al mundo Carmen de Rafael Marés, que era así como se llamaba — adoptó en su firma el apellido de su marido que, en realidad, era Kurz, sin una $t$ entre 
la vuelta de los prisioneros españoles del Gulag tras la muerte de Stalin. Precisamente este fue el tema que desarrolló en dicha obra de una manera novedosa: en lugar de seguir el camino de la literatura española del campo soviético, que sublimó las vivencias de los cautivos y convirtió su penosa experiencia en relatos heroicos y puramente ideologizados, ella se centró en el análisis introspectivo de la mujer que se rencontró con un marido al que creía muerto ${ }^{13}$. La escritora, conocida por su labor en el ámbito de la literatura infantil, pertenece a la generación de autoras de postguerra en la que sobresalen Carmen Laforet, Ana María Matute, Carmen Martín Gaite, Elena Quiroga, Dolores Medio, Elena Soriano y Concha Alós, que durante las décadas de 1950 y 1960, "habían dejado constancia [en sus obras] de la situación de la mujer española y de su función en algunos sistemas de la estructura social de la posguerra" (Mayans, 1991: 191). De todas ellas, y de acuerdo con Montejo Gurruchaga, Kurtz "fue aún más silenciada que algunas de sus compañeras de generación" por los críticos de su época debido, probablemente, a que la denuncia que hizo acerca de la posición de la mujer "manifiesta en este sentido una audacia poco común en las escritoras" (2006: 408).

En esta novela divisionaria, que no fue la única del periodo escrita por una persona que no estuvo en la División Azul, Antonio regresa a Barcelona tras pasar más de diez años en la Unión Soviética, donde fue capturado mientras combatía contra el comunismo ruso ${ }^{14}$. Mientras que él es para las personas que le rodean el merecedor de todo tipo de atenciones por su sufrimiento, Kurtz desplaza su mirada hacia Dominica, su mujer, quien en silencio ha penado primero por la noticia de su desaparición y, posteriormente, por el conocimiento de su cautiverio ${ }^{15}$. La nueva vida del matrimonio,

la $r$ y la $z$ - , fue una mujer cosmopolita desde su genealogía - descendiente de catalanes emigrantes a Estados Unidos, México y Cuba- y por su experiencia vital — vivió un año (1929) en Inglaterra y ocho (1935-1943) en Francia, donde su esposo permaneció retenido en un campo de concentración-. Políglota y con una enorme cultura, sus obras son el reflejo de su propia vida y del trauma de su tiempo. Más allá de su obra narrativa y de su presencia en el diario local La prensa, dedicó gran parte de sus esfuerzos literarios, al menos desde 1962, a la serie de cuentos infantiles de Óscar que ilustró su hija Odile. En 1999 se marchó de este mundo. Algunas de las novelas más relevantes de Carmen Kurtz son Duermen bajo las aguas (1955), La vieja ley (1956), El desconocido (1956), Detrás de la piedra (1958), Al lado del hombre (1961), El becerro de oro (1964), En la punta de los dedos (1968), Al otro lado del mar (1973), El viaje (1975) o Cándidas palomas (1975).

13 Véase Meyers (1988) para comprobar la autotextualidad e intertextualidad de esta novela.

14 Otras novelas divisionarias del momento escritas por personas que no combatieron son La muerte está en el camino (José Luis Martín Vigil, 1956) — que también incide en la temática del regreso del campo-y La última oportunidad (Ramón Zulaica, 1963). En este grupo también puede entrar, por contextualizar parte de su acción en la experiencia de la División Azul, La paz empieza nunca (Emilio Romero, 1957), aunque la temporalidad de esta abarca desde la proclamación de la II República hasta la lucha del maquis. De temática parecida a la novela de Kurtz, y escrita también por una persona que no formó parte de la División Azul, puede verse la obra de teatro El mensaje (Jaime Salom, estrenada en 1955 y publicada en 1963).

15 Las familias de los presos, que daban a sus seres queridos por desaparecidos, tuvieron noticias de ellos desde 1946 gracias a las cartas que recibieron de los antiguos combatientes italianos que compartieron su cautiverio con los españoles y que fueron liberados mucho antes que ellos del Gulag, según ha explicado Rodríguez Jiménez (2008: 150). De hecho, este proceso sucede en la propia novela: "La noticia vino por correo. Una carta de Alemania dirigida al padre. Una de tantas que el abogado recibía. Esperó hasta el mediodía, entre prospectos, avisos de facturas y otras cartas. En la bandeja de la entrada. El nombre del remitente era desconocido por todos y no se le prestó atención. Y el abogado la tomó sin ninguna impaciencia. Primero fue al jardín y al palomar. Enrique Rogers estaba deseando terminar su trabajo para cuidarse del jardín y de sus palomas (...) Luego de ver que, en efecto, los pichones habían roto el cascarón, entró en la casa y rasgó el sobre. Ella estaba en su cuarto y la madre dando instrucciones al servicio. En aquella ocasión la voz del padre atronó la casa y todos acudieron, pues el padre nunca voceaba. Estaba trastornado. Leía en alemán sin darse cuenta de que ni Mercedes ni ella comprendían una sola palabra. Pero al pronto sonó un nombre que comprendieron lodos: Antonio Rogers. Y el abogado daba palmadas a la carta y decía: ‘¿Lo veis? ¿Lo veis? Lo sabía. Está vivo y lo sabía. No he dudado ni un solo momento.' Los ojos le resplandecían y miraba a todos con aire profético. 'Pero... por favor, ¿qué dice?' 
que debería ser un motivo suficiente de alegría, deja al descubierto la incompatibilidad de los dos cónyuges. El clarividente título de la novela ya anuncia que "Antonio sigue siendo un 'desconocido' al final de la obra" (Bertrand de Muñoz, 2001: 136). Se trata de una obra que "analiza la profunda sima abierta por la distancia material y espiritual entre hombre y mujer" (Soriano, 1993: 289) y que ha sido calificada como "una novela de gran modernidad, con una estructura muy racional, muy estudiada, con un armazón narrativo perfecto" (Moix, 1999: 14). A través de la introspección psicológica de los dos miembros del matrimonio, se pone en relieve la problemática a la que tuvieron que enfrentarse aquellas parejas que se reencontraron tras permanecer separados durante un largo periodo de tiempo. En la dualidad de la novela como una de sus principales características ha insistido Roberta Dee Gordenstein:

The use of shifting points of view enables the reader to enter into the psychology of each character and see the irony of opposing opinions regarding the same events (...) Addtionally, the use of multiple perspectives enables the reader to know the protagonists through their own words and thoughts rather than through the interpretations of other characters (1996: 73).

La figura de Dominica, más que con una Penélope que entretiene su espera en tejer y destejer, se asemeja a esas mujeres a quienes habían matado el novio - en las filas sublevadas - en la Guerra Civil y que no volvían a pensar ni siquiera en la posibilidad de compartir su vida con un nuevo hombre ${ }^{16}$. He aquí uno de los problemas que presenta la novela: ella es capaz de amar al hombre al que creía muerto, pero tener el mismo sentimiento por la sombra que ha regresado del horror del campo soviético ya no es posible:

Le dolía el silencio de Antonio. Hubiera preferido una protesta, algo, una explicación que llegara a convencerla. Preguntas. Poco a poco se iría desenredando la madeja. Porque ella ya no comprendía nada. No podía ser. No quería que fuera. Era imposible que, después de haber estado esperando a un hombre durante más de doce años, después de haber amado la memoria, una fotografía, gestos, palabras que guardaban sonido y acento, ahora, cuando el hombre estaba de regreso, presente, ella no le amara (Kurtz, 1986: 161).

La ruptura entre ambos es efectiva incluso en la intimidad. Ahí se observa cómo ella ha pasado de la lealtad hacia el cautivo al rechazo de su cuerpo. Aunque Dominica "se ha impuesto el cumplimiento de los valores sociales de fidelidad a su espo-

\footnotetext{
Ni Mercedes ni ella comprendían del todo. Ella presentía. Y el padre, en aquella ocasión, lanzó una mirada a su mujer. Una mirada llena de palabras. ‘¿No comprendes? Cuando un hijo vive, uno está obligado a saber muchas cosas además del alemán.’ Leyó la carta. Era la de un ex prisionero repatriado. Decía que había conocido a Antonio en uno de los campos de concentración de Rusia y que estaba bien. Que seguramente, ya que ellos volvían a sus hogares, también volverían los españoles. Daba la dirección del campo. Y se escribieron cartas febriles al alemán desconocido y al hijo, al marido, al hermano que continuaba en Rusia. De Alemania vino la respuesta con detalles. De Rusia no vino nada" (1986: 34-35).

16 Roura (1999: 17-18) ha advertido acerca de la lejanía entre el relato homérico y la novela de Kurtz. La cuestión de la mujer que lloraba durante el resto de sus días al hombre caído en la guerra, dentro del bando nacional, remite directamente a la clasificación propuesta por Carmen Martín Gaite para aquellas que quedaban solteras durante la postguerra. La autora distingue, además de aquellas que habían jurado fidelidad eterna a los caídos, a quienes se integraron en el Clero y a quienes se negaron a casarse por mantener su independencia (1994: 43).
} 
so durante tan larga ausencia, ahora se resiste a desempeñar sus deberes de esposa especialmente en el terreno sexual" (Montejo Gurruchaga, 2010: 161). Pero ella no puede eludir este hecho y "se plegará a la autoridad dominante, al sistema de valores patriarcal" (Montejo Gurruchaga, 2010: 161-162), de lo cual se lamenta en un monólogo interior que deja al descubierto la excelente introspección psicológica de los personajes que realiza la autora:

Los labios de Antonio se posaron sobre su mano. Ascendieron por el brazo. Buscaban su boca. Hubiera querido decirle: "Déjame. No me obligues. Ése ha sido tu gran error. Yo no estaba preparada, ¿comprendes?, es decir: estaba aguardando al otro, al que se fue. No al desconocido. Un hombre viene después de una larga ausencia y, al mismo tiempo que de su casa, toma posesión de su mujer. Pero una mujer no es de piedra, Antonio. Esa mujer ha pensado años y años, y en el transcurso de ellos ha ido desenfocando sus pensamientos. No es tan fácil como tú crees. Antes de poseer mi cuerpo hubieras tenido que reconquistar los años perdidos. No sé cómo explicártelo. Tú mismo dices que nada puede ser como antes. Entonces hubieras tenido que empezar otra vez por el principio. Ganarme en tu nueva forma. Lo malo ha sido eso: tomar posesión de una mujer como si esa mujer, por el único hecho de pertenecerte, hubiera permanecido inmóvil como las piedras de tu casa” (Kurtz, 1986: 167-168).

Sirven estas palabras de Dominica para contemplar cómo, en el relato, la mujer se ve obligada a consentir a los requerimientos del hombre. Así se expresa en la novela cuando se lee que era "ella la que debía ceder (...) la que (a los ojos de todos) no había sufrido", quien "debía ayudar a quien durante años y años no hizo más que luchar contra el sufrimiento" (1986: 212). Todas las desgracias se atribuyen al hombre y ella, daño colateral de la experiencia divisionaria, no cuenta para ninguno de los lamentos de las personas de su alrededor. Carmen Kurtz expone cómo en esta situación la esposa se ve obligada a sacrificar sus intereses en beneficio del marido: "Es decir: en los casos de diferencia, la mujer estaba supeditada al hombre. Siempre ante él, en estado de inferioridad. Si él quería, ella debía estar presta y mostrarse complacida. Si él no quería, ella debía acallar su cuerpo, olvidarse de su juventud, secarse lentamente y pedir a los años un poco de sosiego" (227). La imposibilidad por parte de Dominica de saciar sus deseos acaba en un intento de suicidio. Aunque Antonio evita tan trágico desenlace puede apreciarse cómo este acto es efecto de su marcha al frente del Este y los años en el Gulag. Kurtz consigue cambiar el paradigma e invertir la tendencia del héroe regresado por la de los problemas que traía consigo del campo de trabajo ruso. Siempre cabe la posibilidad de que el retorno signifique la sucesión de una serie de desgracias. El padre había adivinado que esto ocurriría y así se lo hace saber a su hijo:

Me lo figuraba, Antonio. No quise hablarte. Lo sucedido no puede juzgarse, pues resulta imposible juzgar la sinrazón misteriosa que de dos seres unidos legalmente hace dos adversarios, dos enemigos, dos desconocidos. Ni yo ni nadie puede condenar a Dominica. Ella quiso desaparecer y no lo ha logrado. Luchó tanto, que se agotó en la lucha. Seguramente lo mejor de ella, estaba aniquilado cuando cometió el acto. Compréndela. No tenía dónde refugiarse. Ningún reproche podía dirigirte. Volvías, volviste a casa aureolado con tu nueva personalidad de héroe, de mártir. Y ella, ellas, Antonio, no desean ser esposas de héroes. Dominica amó al hombre que eras, no al que ha vuelto (1986: 297). 


\section{Conclusiones}

La mujer fue para el proyecto de la Falange "una sombra de destino en lo universal" (Sánchez López, 1990). Pero algunas de ellas no se resignaron a cumplir un papel secundario en la vida cotidiana del franquismo y tomaron parte, hasta el límite que la dictadura les permitió, en la vida pública o en las acciones directas del fascismo español. Los dos conflictos en los que este se vio envuelto - la contienda cainita y la II Guerra Mundial - no se entenderían sin la intervención de las mujeres. Las afines al Régimen fueron recordadas por sus camaradas masculinos en los relatos de la División Española de Voluntarios, para quienes las madrinas de guerra y las enfermeras representaron a las féminas idealizadas por la propaganda franquista. Aquellas que habitaban los lugares por los que los divisionarios pasaron en su camino hacia el Este fueron normalmente cosificadas en las memorias y novelas que escribieron tras su regreso. Con ellas su comportamiento fluctuó entre la consideración de la mujer como parte del botín y la representación de un amor bucólico que en varios ejemplos rozó la cursilería —entendida esta como un falso enamoramiento- . Esta pudo, en el caso de las indígenas soviéticas, ocultar la verdadera relación que se estableció entre los soldados y ellas, es decir, la imposición de la voluntad del conquistador frente a la necesidad del conquistado sumiso.

Aquí finalizaría la aproximación al rol femenino en la literatura divisionaria si el corpus no guardara la sorpresa de El desconocido. Su autora, Carmen Kurtz, otorga el papel principal a la mujer que esperó pacientemente al hombre que cumplía con la misión anticomunista. La escritora da voz, a través de Dominica, a las madres, esposas y novias que tuvieron que aceptar con resignación que sus seres queridos varones se marcharan a la guerra con la incertidumbre de si sería la despedida la última vez en la que disfrutarían de su presencia. Kurtz amplía los efectos del conflicto y añade al trauma del soldado el de la familia que entrega una vida por una causa política. Además de ser una novela valiente para la década de 1950, en la que se cuestiona la estabilidad de una de las instituciones fundamentales de la vida social de la época, el matrimonio, aborda el tema del Gulag. Se trata de un escenario que tuvo eco únicamente en la literatura española con los testimonios de los regresados de los campos de trabajo soviéticos en el mismo periodo en el que apareció esta novela y del que en España se conoce, sobre todo, la recepción y el uso publicista que tuvo la traducción del texto de Alexandr Solzhenitsyn.

Para finalizar, se comprueba con este acercamiento que la representación de la División Azul en las letras, un tipo de obras que tuvo cierto éxito en su momento y que hoy ha quedado relegado en los márgenes del canon, sirve para explorar aspectos tan interesantes como el papel de las mujeres durante la dictadura o rescatar a una escritora prácticamente olvidada como Carmen Kurtz. Actualmente, el prisma acerca del rol femenino en las novelas que toman como trasfondo a la División Española de Voluntarios ha variado, lo que permite que la soledad de Dominica en las letras divisionarias hasta fechas recientes sea cosa del pasado. Españolas, alemanas y soviéticas formaron parte de uno de los episodios más intensos de las letras y de la Historia del franquismo y, como demuestra este estudio, poco a poco su memoria es restituida con rigor y dignidad ${ }^{17}$.

17 Montero (2016) ha publicado recientemente una novela ambientada en la Guerra Civil y en la II Guerra Mundial en la que Lena, una enfermera del bando nacional, actúa como tal durante el asedio de Oviedo y en el frente del Este con la División Azul. Incluso la autora describe, en esta novela, una tipología imposible de encontrar en las narraciones divisionarias clásicas: la de una enfermera antigua republicana que se alista en la misión anticomunista. 


\section{Obras citadas}

Agustí Roca, Carme, Rússia és culpable! Memòria i record de la División Azul, Lleida, Pagès editors, 2003.

Albaladejo, Tomás, Semántica de la narración: la ficción realista, Madrid, Taurus, 1992.

Arasa, David, Los españoles de Stalin, Barcelona, Belacqva, 2005.

Archivo General de la Administración (AGA), Alcalá de Henares (Madrid).

Bertrand de Muñoz, Marysse, Guerra y novela: la guerra española de 1936-1939, Sevilla, Alfar, 2001.

Bescos Torres, Jesús, "Misiones de Sanidad española en el extranjero: la Sanidad Militar en la División Azul", Medicina Militar: Revista de Sanidad de las Fuerzas Armadas de España, 51.2 (1995), pp. 184-193.

Blanco, Juan Eugenio, Rusia no es cuestión de un día... Estampas de la División Azul, Madrid, Publicaciones Españolas, 1954.

Blasco Herranz, Inmaculada, "Género y nación durante el franquismo", en Stéphane Michonneau y Xosé M. Núñez Seixas (coords.), Imaginarios y representaciones de España durante el franquismo, Madrid, Casa de Velázquez, pp. 49-73.

Bowen, Wayne. H., Spaniards and Nazi Germany: collaboration in the new order, Columbia - London, University of Missouri Press, 2000.

Bullón de Mendoza, Alfonso, “Introducción”, en Alfonso Bullón de Mendoza y Luis E. Togores (coords.), La otra memoria, Madrid, Actas, pp. 11-16.

Caballero Jurado, Carlos, "La violencia política frentepopulista y los orígenes de la División Azul”, en Alfonso Bullón de Mendoza y Luis E. Togores (coords.), La otra memoria, Madrid, Actas, 2011, pp. 802-826.

-, y Rafael Ibáñez Hernández, Escritores en las trincheras: la División Azul en sus libros, publicaciones periódicas y filmografía (1941-1988), Madrid, Barbarroja, 1989.

Cenarro Lagunas, Ángela, "Historia y memoria del Auxilio Social de Falange", Pliegos de Yuste, 11-12 (2010), pp. 71-74. En línea: http://www.pliegosdeyuste.eu/n1112pliegos/ pdfs/71-74.pdf (Último acceso: 12 de junio de 2018).

Chacón, Dulce, "Prólogo", en Manuel de Ramón y Carmen Ortiz, Madrinas de guerra: cartas desde el frente, Madrid, La Esfera de los Libros, 2003, pp. 17-20.

Crespo, Alberto, De las memorias de un combatiente sentimental, Madrid, Haz, 1945.

Diego, Juan de, "Después de una ausencia de varios meses... llegan a Madrid 30 enfermeras de la División Azul", Y. Revista para la mujer, 55 (1942), pp. 12-13 y 49.

Farré Albiñana, Jaime, 4 Infantes, 3 luceros, Tetuán, [s.n.] (Tipografía Librería Escolar), 1949.

Gallardo rodríguez, Pilar, "La mujer militar en las Fuerzas Armadas", Cuadernos de estrategia (Ministerio de Defensa), 157 (2012), pp. 139-174.

Gallego Méndez, María Teresa, Mujer, Falange y franquismo, Madrid, Taurus, 1983.

Giménez Muñoz, Mari Carmen, "La instrucción de enfermeras como labor ideológica de la Sección Femenina (1939-1953)", Arenal: Revista de historia de las mujeres, 23 (2) (2016), pp. 267-286. En línea: http://revistaseug.ugr.es/index.php/arenal/article/ view/3047/5116. (Último acceso: 12 de junio de 2018).

Gómez Tello, José Luis, Canción de invierno en el Este. Crónicas de la División Azul, Barcelona, Luis de Caralt, 1945.

González-Allende, Iker, Líneas de fuego: género y nación en la narrativa española durante la Guerra Civil (1936-1939), Madrid, Biblioteca Nueva, 2011.

González Martín, Francisco Javier, "Cultura y acción. La División Española de Voluntarios entre la historia y la literatura", en Antonio Manuel Moral Roncal y Francisco Javier 
González Martín (coords.), Los españoles ante la Segunda Guerra Mundial: politicas y recuerdos, Alcalá de Henares, Universidad de Alcalá, Servicio de Publicaciones, 2015, pp. 99-130.

Gordenstein, Roberta Dee, The Novelistic World of Carmen Kurtz, Michigan, UMI Dissertation Services, 1996.

Gracia, Jordi, "Rehacer la memoria: cultura y fascismo en la España democrática", Olivar: revista de literatura y cultura españolas, VII (8) (2006), pp. 87-106. En línea: https:// www.olivar.fahce.unlp.edu.ar/article/view/OLIv07n08a05. (Último acceso: 12 de junio de 2018).

-, La vida rescatada de Dionisio Ridruejo, Barcelona, Anagrama, 2008.

Grandes, Almudena, El corazón helado, Barcelona, Tusquets, 2015.

Guzmán Mora, Jesús, Visiones de Rusia en la narrativa española: el caso de la División Azul, Tesis doctoral, Universidad de Salamanca, 2016. En línea: https://gredos.usal.es/jspui/ handle/10366/132960 (Último acceso: 24 de junio de 2018).

Guzmán Mora, Jesús, "La División Azul en Y. Revista para la mujer (1941-1943)”, Creneida: anuario de literaturas hispánicas, 6 (2018), pp. 526-551. En línea: https://www.uco. es/ucopress/ojs/index.php/creneida/article/view/11556/10517 (Último acceso: 23 de julio de 2019).

Hernández Navarro, Antonio José, Ida y vuelta, Madrid, Espasa-Calpe, 1971.

Huecar, Martín, "Riesgo y ventura de una enfermera", Y. Revista para la mujer, 43 (1941), pp. 42 y 48.

Ibáñez Hernández, Rafael, "Españoles en las trincheras: la División Azul”, en Stanley G. Payne y Delia Contreras (dirs.), España y la Segunda Guerra Mundial, Madrid, Editorial Complutense, 1996, pp. 55-88.

Jiménez y Malo de Molina, Víctor José, De España a Rusia: 5.000 kms. con la División Azul, Madrid, Imprenta de Madrid, S. L, 1943.

Kleinfeld, Gerald R., y Lewis A. Tambs, La División Española de Hitler: la División Azul en Rusia, Madrid, Editorial San Martín, 1983.

Kurtz, Carmen, El desconocido, Barcelona, Planeta, 1986.

Lejeune, Philippe, El pacto autobiográfico y otros estudios, Madrid, Megaluz-Endymion, 1994.

López-Covarrubias, J. Andrés, Toledanos en la División Azul: Entre la memoria y el olvido, Toledo, Ediciones Covarrubias, 2012.

López Pavia, Cristina, "Las heroínas de Carmen Kurtz”, La Vanguardia (Culturas), 15 de agosto de 2007, pp. 10-11.

Mainer, José-Carlos, "La segunda guerra mundial y la literatura española: algunos libros de 1940-1955”, en José Luis García Delgado (ed.) y Manuel Tunón de Lara (dir.), El primer franquismo. España durante la segunda guerra mundial: V Coloquio sobre Historia Contemporánea de España, Madrid, Siglo XXI de España, 1989, pp. 245-268.

Martín Gaite, Carmen, Usos amorosos de la posguerra española, Barcelona, Anagrama, 1994.

Mayans Natal, María Jesús, Narrativa feminista española de posguerra, Madrid, Editorial Pliegos, 1991.

Moix, Ana María, "La generosidad de Carmen Kurtz”, Cuadernos de estudio y cultura. Homenaje a Carmen Kurtz (1911-1999): Ponencias presentadas en el acto celebrado en el Col-legi de Periodistes de Catalunya, el día 27 de mayo de 1998, 11 (1999), pp. 13-16. En línea: http://www.acec-web.org/PDF/CUAD/11.PDF. (Último acceso: 9 de junio de 2017). 
Montejo Gurruchaga, Lucía, "La narrativa de Carmen Kurtz: compromiso y denuncia de la condición social de la mujer española", Arbor: Ciencia, pensamiento y cultura, 719 (2006), pp. 407-415. DOI: http://dx.doi.org/10.3989/arbor.2006.i719.40.

-, Discurso de autora: género y censura en la narrativa española de posguerra, Madrid, Universidad Nacional de Educación a Distancia, 2010.

Montero, Carla, El invierno en tu rostro, Barcelona, Plaza \& Janés, 2016.

Moreno Juliá, Xavier, La División Azul: Sangre española en Rusia, 1941-1945, Barcelona, Crítica, 2005.

Moya, Antonio-Prometeo, Últimas conversaciones con Pilar Primo de Rivera, Barcelona, Caballo de Troya, 2006.

Myers, Eunice D., "Auntotextuality and Intertextuality in El desconocido by Carmen Kurtz", Hispania, 71.1 (1988), pp. 43-49.

Negreira, Juan, Voluntarios baleares en la División Azul y Legión Azul, 1941-1944, Palma de Mallorca, Edicions Miramar, 1991.

Negró Acedo, Luís, Discurso literario y político del franquismo, Madrid, Foca, 2008.

Núñez Seixas, Xosé M., "Los vencedores vencidos: La peculiar memoria de la División Azul, 1945-2005", Pasado y memoria: Revista de historia contemporánea, 4 (2005), pp. 83-116. DOI: http://dx.doi.org/10.14198/PASADO2005.4.06

_, "Del ruso virtual al ruso real: El extranjero imaginado del nacionalismo franquista", en Xosé Manoel Núñez Seixas y Francisco Sevillano Calero (coords.), Los enemigos de España: imagen del otro, conflictos bélicos y disputas nacionales (siglos XVI-XX): Actas del IV Coloquio Internacional de Historia política, Madrid, Centro de Estudios Políticos y Constitucionales, 2010, pp. 233-265.

—, "Dionisio Ridruejo y la experiencia de la División Azul (1941-1942)", en Dionisio Ridruejo, Cuadernos de Rusia: Diario 1941-1942, Madrid, Fórcola, 2013, pp. 9-52.

-, Camarada invierno: Experiencia y memoria de la División Azul (1941-1945), Barcelona, Crítica, 2016.

Poyato Galán, Juan Manuel, Bajo el fuego y sobre el hielo: la sanidad en la campaña de la División Azul, Madrid, Actas, 2015.

Rabazas Romero, Teresa, y Sara Ramos Zamora, "La construcción del género en el franquismo y los discursos educativos de la Sección Femenina", Encounters on Education, 7 (2006), pp. 43-70. En línea: http://qspace.library.queensu.ca/bitstream/handle/1974/636/ romero_zamora.pdf?sequence=1\&isAllowed=y. (Último acceso: 21 de junio de 2018).

Reverte, Jorge M., La División Azul, 1941-1944, Barcelona, RBA, 2011.

Rey-Ximena, José, "La espía que volvió loco a Ridruejo", El Mundo, 15 de noviembre de 2009. En línea: http://www.elmundo.es/suplementos/cronica/2009/735/1258239610.html (Último acceso: 17 de mayo de 2017).

Richmond, Kathleen, Las mujeres en el fascismo español: la Sección Femenina de la Falange, 1934-1959, Madrid, Alianza, 2004.

Ridruejo, Dionisio, Cuadernos de Rusia: diario 1941-1942, Madrid, Fórcola, 2013.

Rodríguez Jiménez, José Luis, De héroes e indeseables: La División Azul, Madrid, Espasa, 2007.

_ , "El papel de las familias en las gestiones para la liberación de los prisioneros de la División Española de Voluntarios en la URSS”, Historia del presente, 11 (2008), pp. 141-164. En línea: http:/historiadelpresente.es/sites/default/files/revista/articulos/11/11.8joseluisrodriguezjimenezelpapeldelasfamiliasenlasgestionesparalaliberaciondelosprisionerosdeladivis.pdf. (Último acceso: 9 de junio de 2017).

Rodríguez Puértolas, Julio, Historia de la literatura fascista española, 2 vols., Madrid, Akal, 2008. Romero, Luís, Tudá (Allá), Barcelona, Acervo, 1957. 
Roura, Assumpta, "Carmen Kurtz: apuntes y reflexiones sobre la obra El desconocido", Cuadernos de estudio y cultura. Homenaje a Carmen Kurtz (1911-1999): Ponencias presentadas en el acto celebrado en el Col-legi de Periodistes de Catalunya, el día 27 de mayo de 1998, 11 (1999), pp. 17-20. En línea: http://www.acec-web.org/PDF/CUAD/11.PDF. (Último acceso: 9 de junio de 2017).

Royo, Rodrigo, ¡Guerra! Historia de Luis Pablos: novela, Madrid, [s.n.] (Gráficas Ultra), 1944. —, El sol y la nieve, Madrid, Talleres Gráficos CIES, 1957.

Ruiz Ayúcar, Ángel, La Rusia que yo conocí, Madrid, Ediciones del Movimiento, 1954.

Ruiz Franco, Rosario, "Mujeres para el frente ruso: la Sección Femenina de Falange y la División Azul", en Antonio Manuel Moral Roncal y Francisco Javier González Martín (coord.), Los españoles ante la Segunda Guerra Mundial: políticas y recuerdos, Alcalá de Henares, Universidad de Alcalá, Servicio de Publicaciones, 2015, pp. 19-44.

Salvador, Tomás, División 250, Barcelona, Destino, 1970.

Sánchez López, Rosario, Mujer española, una sombra de destino en lo universal: trayectoria histórica de Sección Femenina de Falange (1934-1977), Murcia, Universidad de Murcia, 1990.

Saz Campos, Ismael, Fascismo y franquismo, [Valencia], Universitat de València, 2004.

Suárez Fernández, Luis, Crónica de la Sección Femenina y su tiempo, [Madrid], Asociación Nueva Andadura, D. L., 1992.

Soriano, Elena, Literatura y vida. II Defensa de la literatura y otros ensayos, Barcelona, Anthropos, 1993.

Todorov, Tzvetan, Los abusos de la memoria, Barcelona, Paidós, 2000.

Torres García, Francisco, "Mentira y propaganda sobre la División Azul: Martínez Reverte y El País", Diario Ya (sin fecha). En línea: http:/www.diarioya.es/content/mentira-y-propaganda-sobre-la-división-azul-mart\%C3\%ADnez-reverte-y-el-pa\%C3\%ADs. (Último acceso: 12 de junio de 2018).

Torres García, Francisco, Cautivos en Rusia: los últimos combatientes de la División Azul, Madrid, Actas, 2018.

Trapiello, Andrés, Ayer no más, Barcelona, Destino, 2012.

Urquijo, Alfonso de, Cuando empuñamos las armas: la pequeña historia de una familia numerosa entre 1936 y 1942, Madrid, Editorial Moneda y Crédito, 1973.

Vadillo, Fernando, Orillas del Voljov, Barcelona, Marte, 1967.

Wahnón, Sultana, La estética literaria de la posguerra: Del fascismo a la vanguardia, Amsterdam, Atlanta, Rodopi.

Ydígoras, Carlos María, Algunos no hemos muerto, Madrid, Editorial Arrayán, 1963.

Yuval-Davis, Nira, "Género y nación: articulaciones del origen, la cultura y la ciudadanía", Arenal, 3 (2) (1996), pp. 163-175. En línea: http://www.memoriadigitalvasca.es/bitstream/10357/33944/1/138181.pdf. (Último acceso: 21 de junio de 2018).

—, Género y nación, Lima, Flora Tristán, 2004. 